\title{
WAYS OF ARISING OF PUBLIC AWARENESS AND EDUCATIONAL LEVEL IN SOLID WASTE MANAGEMENT SPHERE OF ST. PETERSBURG
}

\author{
Maria Lyubarskaya \\ St. Petersburg State University \\ of Engineering and Economics, Russia
}

\begin{abstract}
Whereas solid waste products influence deterioration of the environment and reduce quality of human life, intensification of activity on creation the effective solid waste management (SWM) system is necessary. In the usual conditions of management there is a necessity of application of the integrated approach allowing comprehensively to evaluate usual situation in the sphere of SWM and to find the most rational solutions. It demands significant improvement of the system of education, training and improvement of professional skill of technicians and managers for the given sphere. Use of experience of the Nordic countries in the field of scientific and practical researches on the given problem and in the organization of education and training specialists, will assist to the achievement of the object and solving the connected problems.

For Elaborating of Educational course on Solid Waste Management for students of Saint Petersburg State University of Engineering and Economics the following methods was used:

- Revealing of problems in the SWM sphere in St Petersburg - organizational, legislative, technical, technological, psychological, informational, educational and environmental;

- Studying of the experience of the organizational charts for the SWM in big and small cities of adjacent Nordic countries, realization of the SWOT-analysis and benchmarking of operating of these systems;

- Development of measures on improving organizational, economic and legal principles of SWM, on stimulation of innovation activity for attraction modern engineering and technologies, and also on radical improvement of education and training for improving professional skill of personnel for this sector of economy.
\end{abstract}

\section{KEYWORDS}

Solid waste management, ecological education, economic and legal principles, modern engineering and technologies, training course, public awareness.

\section{INTRODUCTION}

People aspire to improve conditions of the existence due to achievements of scientific and technical progress, increasing thus a degree of pollution of territories on which live. The ecological culture of the population is at the lowest level, and the outlined tendencies have obviously negative character.

The interrogation of residents of Russia lead by the research organizations has shown that the congestion of solid waste is one of the major ecological dangers. In new conditions the main 
criterion of progress of mankind should become quality of the population's life, one of which important components is the effective organization of solid waste management [1].

In connection with an aggravation in cities of the environmental problems caused in great volumes of solid waste generation and an inefficiency of management by sanitary clearing, as well as with influence of these problems on all economic complex of cities, there was an indispensability of strengthening of personnel base in the field of municipal economy and municipal management.

One of directions of strengthening of personnel base is preparation of heads of all levels and the economists possessing as knowledge of bases of technologies of solid waste management, and owning skills of effective application of methods of the integrated communications, logistics.

The output from the created situation within the framework of traditional administrative methods and at preservation of current technologies is practically impossible. In the usual conditions of management there is a necessity of application of the integrated approach allowing comprehensively to evaluate usual situation in the sphere of SWM and to find the most rational solutions. There are two main reasons of absence of the effective SWM system:

- Insufficient understanding of the given problem by people and authorities at all levels;

- Absence of the qualified experts in this field, who has a progressive view to this problem.

Besides insufficient attention to strategic and tactical planning for safe handling of waste products has resulted in the absence of an adequate terminology in the given sphere. Absence of a complex policy, which unites actions under the handling of waste products and restoration of resources, burdens this situation [2].

\section{ACTIONS FOR IMPRUVING OF ECOLOGILAL EDUCATION}

Adjacent Nordic countries - Finland, Sweden, Norway and Denmark - have already the experience of the system construction in SWM. During its operating some administrative and technological decisions have come to light, there is a certain statistics. The research course on SWM for students and Ph.D. students from Russian should be created on the basis of the careful analysis of the mechanism and results of operating of SWM systems in big and small cities of Nordic countries. It will allow to avoid many mistakes and to make faster rates for promotion of the planned purpose. Use of experience of Nordic countries for St Petersburg in view of the territorial affinity, similar climatic conditions and some other factors is especially important.

One of the factors, preventing introducing efficient system of the SWM is a fragmentariness of the problem's analysis, allocation either separate stages or separate operating elements. All stages of the handling with the solid household waste products formed in big cities are inextricably related between themselves. Realization of actions for improving, for example, of only transportation of household waste products will not give such effect, as formation an integrated system of the SWM. However, the development of optimization of the handling with waste products at the certain stage within the framework of the integrated system is also necessary [3].

It demands significant improvement of the system of education, training and improvement of professional skill of technicians and managers for the given sphere. Use of experience of the Nordic countries in the field of scientific and practical researches on the given problem and in the organization of education and training specialists, will assist to the achievement of the object and solving the connected problems.

For Elaborating of Educational course on Solid Waste Management for students of Saint Petersburg State University of Engineering and Economics the following methods was used: 
Revealing of problems in the SWM sphere in St Petersburg - organizational, legislative, technical, technological, psychological, informational, educational and environmental;

Studying of the experience of the organizational charts for the SWM in big and small cities of adjacent Nordic countries, realization of the SWOT-analysis and benchmarking of operating of these systems;

Development of measures on improving organizational, economic and legal principles of SWM, on stimulation of innovation activity for attraction modern engineering and technologies, and also on radical improvement of education and training for improving professional skill of personnel for this sector of economy.

The following actions should be realized:

The analysis of various aspects of SWM system for solid waste products in St Petersburg;

The comparative analysis of the legislative bases for the SWM in Russia (at federal and municipal levels) and the EU countries;

Monitoring of references and materials of periodicals on problems of SWM in cities with the purpose of generalization of available problems and the analysis of used approaches to their solving;

Marketing research of new methods of SWM, including organizational and economic principles, legal bases, engineering and technology, programs of education, training and improvement of professional skill of managers and technicians and didactical and instructional materials for the given sphere;

Allocation of target groups (different age groups of the population, representatives of authorities, representatives of the housing organizations, processing and transport companies) and the development educational and training programs for them to prepare in the best manner changing of the system of the SWM using a method of integrated communications (Public Relations + Marketing + Promotion).

\section{EDUCATIONAL COURSE ON SOLID WASTE MANAGEMENT FOR STUDENTS}

The integrated educational course on SWM for students of Saint Petersburg State University of Engineering and Economics include the following themes:

Introduction. Course objectives and tasks. Structure of the course. Current environmental problems of cities and influence on them of solid waste.

Module 1. The characteristic of solid waste handling process in cities. Glossary. Classification of solid waste. Key processes and participants in solid waste handling: waste generation (sources, volume and structure), waste collecting and its schemes (including problems of selecting and sorting), waste transportation, waste treatment (recycling, incineration for energy production with and without a gasification process, composting and landfilling).

Module 2. Legislation base for SWM. Laws of the Russian Federation and regional acts in the environment and SWM: rights, duties and responsibilities of participants; licensing for activities in solid waste handling; standards and certification. Judiciary practical cases of disputes in SWM. The legislation of Nordic countries and the EU. Trends in improving of legislative base for SWM.

Module 3. Environmental aspects. Evaluation of environmental aspects of solid waste handling. Cross-border impact of solid waste generation and handling in neighbor countries. Ecological expertise of projects in SWM. Cooperation with state and municipal authority bodies and non-governmental institutions.

Module 4. Organizational chart for solid waste handling. Integrated approach to solid waste handling processes. General chart and its specifications in Russia (including St Petersburg), Nordic countries, the rest countries of the EU and USA. Cooperation between various participants (authority bodies, householders and industry, transportation, processing plants 
and landfills). Employees level: education, qualification, salaries and benefits for stimulating proper executing.

Module 5. Financial and economic analysis. Pricing and tariffs in SWM. Financing schemes. Stimulation of business development in SWM: additional incomes from realization of solid waste products, including mortgaging cost for recycling, loans and tax privileges, venture and leasing schemes.

Module 6. Information system for SWM. Statistical monitoring and databases. Evaluation of capacities of enterprises for handling of solid waste. Different methods for forecasts of solid waste generation and accumulation in the countries and regions including economical and mathematical ones.

Module 7. Integrated communications in SWM. Marketing researches in solid waste handling (including benchmarking to different countries and regions and the SWOT-analysis). Development of the market of technologies and solid waste treatment products. PR-activities in SWM including psychological trainings for different participants of the process (population, managers and technicians of enterprises, representatives of authority bodies). Specific activities for children and young people.

Module 8. Logistics in SWM. Using of logistics principles in the sphere of solid waste management. Logistic approach to a background of methods for forecasting of solid waste generation. Management of information flows in SWM system on the basis of logistical principles. Application of methods of logistics for optimization of management of protractorswhich ТБО.

Module 9. Influence of SWM system on sustainable development of regions. Classification and the analysis of factors of influence of SWM system on sustainable development of regions. Economical factors of influence. Ecological factors of influence. Social factors of influence.

Module 10. The organization of management of specific solid waste flows. Packing and packing waste. Waste of electrical and electronic equipment (WEEE). Hazardous waste. Used batteries and accumulators. Paper for recycling. Biodegradable household waste. Construction and demolition waste. Used tyres. End-of-life vehicles. Clinical waste. Sewage sludge.

Module 11. Strategic planning of SWM system development. Structure and methods of creation of the strategic plan for development of solid waste management system. Stages of planning. Statement of objectives. The organizational and economical mechanism of realization of the developed strategy.

Module 12. Evaluation of efficiency of SWM operating. Methods of efficiency evaluation and its elements: economic efficiency, environmental efficiency and social efficiency. Integrated parameters of efficiency. The current expenses for operating of a system of sold waste handling. Necessary investments for its modernization.

\section{RESULTS AND DISCUSSION}

In recent years all over the world the aggravation of environmental problems is observed. Cities faced a lot of ecological problems: on the one hand, there is a problem of an increase of volume of solid waste, and with another - a problem of territorial limitation for places of their landfilling. It finds reflection in an increase of cost of actions of household waste handling, in particular, costs of their transportation. Unfortunately, the traditional approach assumes the attitude to waste extremely as to garbage of which it is necessary to get rid.

At the same time the solid waste accumulated on official landfills both not authorized dumps represents a valuable source of raw material for the industry, constructions and other spheres, and their rational use can become a basis for increase of economic potential of territory.

All aspects of a "garbage" problem - both ecological, and economic, and social - do necessary 
perfection of management of city waste at all stages.

In the developed conditions of managing there is an indispensability of application of the complex approach allowing comprehensively to estimate developed situation in solid waste management sphere and to find the most rational administrative decisions.

Objective of the given training course - preparation of the experts possessing sufficient knowledge for the complex decision of problems in solid waste management sphere.

\section{CONCLUSIONS}

For arising of public awareness and educational level in solid waste management sphere of St. Petersburg it's necessary:

- To implement complex approach for preparing specialists for the companies which work in this field and in authority bodies which is responsible for SWM;

- To implement combination of economical and technical aspects, theoretical lectures, seminars, practical cases and study visits during holding of the integrated educational course on SWM.

\section{REFERENCES}

[1] Lyubarskaya M.A., Chekalin V.S. Innovative approach to solid waste management in regions on the basis of principles of logistics. - St. Petersburg: Publishing house "Info-da", 2005.

[2] Sergeeva V.G. Formation of complex management system of sanitary clearing sphere of a city. - St. Petersburg:St. Petersburg State University of Engineering and Economics, 2004.

[3] Solid Waste Management for Economically Development Countries / Luis F. Diaz, George M. Savage, Linda L. Eggerth, Clarence G. Golueke. — Hercules: CalRecovery, 1996. 